functional demands of the post-larval stage in a species' life history (possibly quite different to the adult period) are quite important.

Differences in the relative rate of disc plate and arm development between some direct and indirect species and shallow and deep sea forms are tentatively suggested.

\title{
Preliminary observations on the near-bottom ichthyofauna of the Rockall Trough: a contemporaneous investigation using commercial- sized midwater and demersal trawls to $100 \mathrm{~m}$ depth
}

\author{
N. R. Merrett and J. Badcock \\ Institute of Oceanographic Sciences, Brook Road, Wormley, Godalming, Surrey \\ GU8 5UB, U.K.

\section{S. Ehrich} \\ Institut für Seefischerei der Bundesforschungsanstalt für Fischerei, Hamburg, \\ Germany \\ and
}

\section{P. A. Hulley}

South African Museum, Cape Town, South Africa

The continental slope both truncates the distribution of the oceanic meso- and bathypelagic ichthyofauna and provides the headquarters of a diverse assemblage of demersal fishes. While demersal forms are well adapted to such an environment, the morphology of pelagic species differs conspicuously and seems better suited to an open ocean habitat. Submersible observations, together with a small body of near-bottom closing net data and records of pelagic fish in stomachs of demersal species, mainly constitute the scant knowledge of the interactions of these distinct faunal elements.

In May, 1983, during cruise 58 of F.R.V. Walther Herwig (Institut für Seefischerei, Hamburg) preliminary investigations were made into the swimming layers of the near-bottom ichthyofauna of the Rockall Trough $\left(56^{\circ} 18^{\prime}-44^{\prime} \mathrm{N}\right)$ using much larger nets than employed hitherto. Over a five-day period, five demersal trawls were made on the Feni Ridge and six on the Hebridean Terrace at approximately $200 \mathrm{~m}$ intervals from $200-1000 \mathrm{~m}$ soundings, using a 200 foot bottom trawl (200' BT-nominal mouth opening $22 \mathrm{~m} \times 6 \mathrm{~m}$ headline height). In addition, nine Engels midwater trawl (1600 PT-mouth opening $30 \mathrm{~m} \times 20 \mathrm{~m}$ high) collections were made in similar localities (Feni Ridge-four; Hebridean Terracefive) and depths fished with the footrope (0) 3-18 (60) $\mathrm{m}$ above the sea bed, together with a set of mid-Trough samples from $100,400,700$ and $1000 \mathrm{~m}$ depth 
over $2550-2620 \mathrm{~m}$ soundings. Except for three tows of $45-75 \mathrm{mins}$ duration, all hauls were for 30 mins at depth and towed at $4.0 \mathrm{kts}$.

The total collection yielded some 40,000 fish weighing in excess of $6300 \mathrm{~kg}$ (1600 PT-23,000 fish; > 300 kg (three samples unweighed): 200' BT-17,000 fish; $6000 \mathrm{~kg})$ ). One hundred and eight species were sampled of which nineteen were peculiar to the mid-Trough catches and only twenty-seven were common to both types of gear. Considering relative abundance, however, thirty-eight species only comprised $>3 \%$ of any one sample. At this level, consistent differences in overall composition are evident among the $200^{\prime}$ BT demersal slope, and 1600 PT pelagic slope and mid-Trough samples (Fig. 1). The only mesopelagic species to be ranked

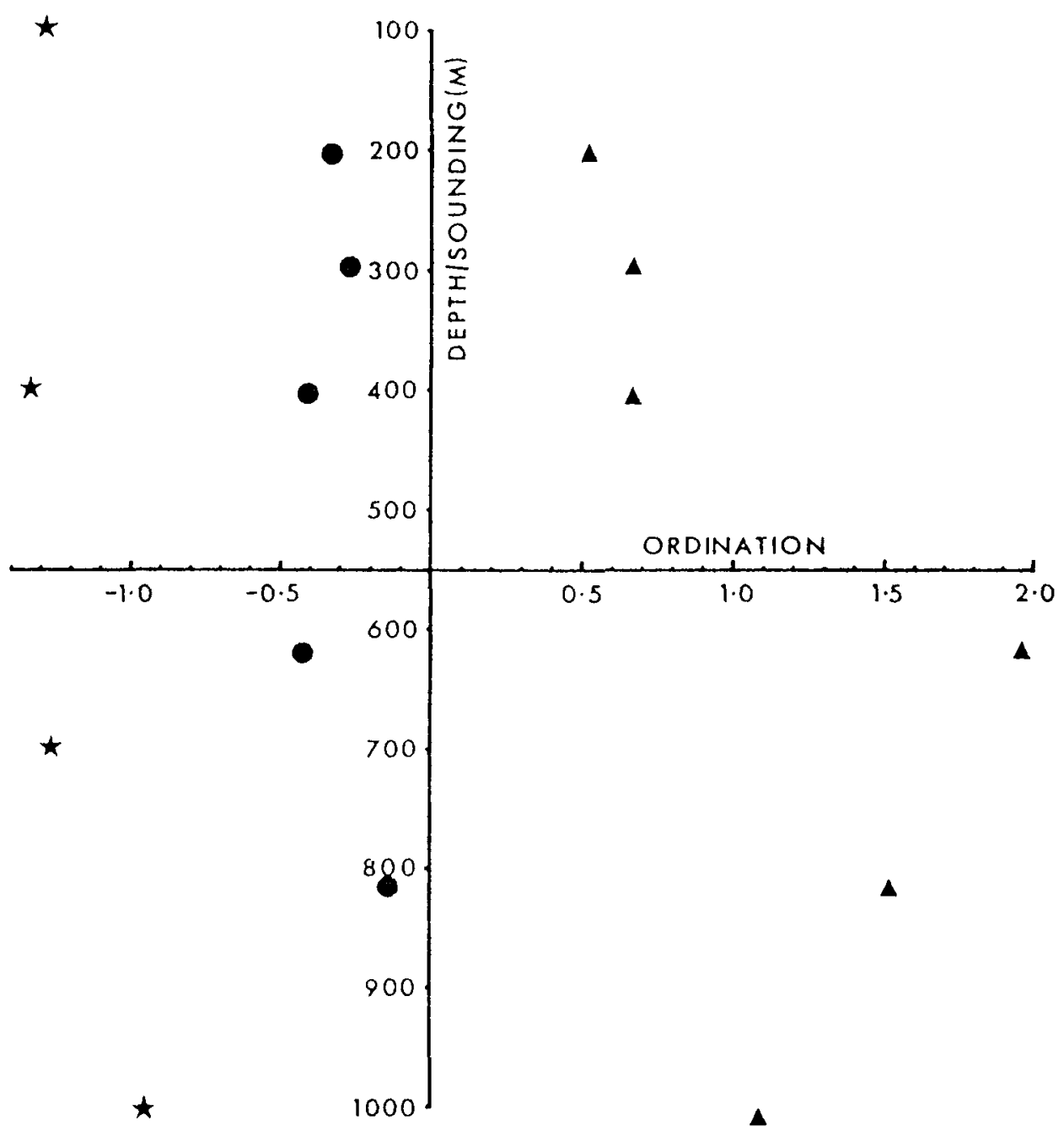

Figure 1. Comparison of the overall composition of the $200 \mathrm{ft} \mathrm{BT}$ demersal slope $(\mathbf{\Delta})$ and the $1600 \mathrm{PT}$ pelagic slope (†) and mid-trough ( $\star$ ) samples. Plot of one-dimensional ordination (by multidimensional scaling) of percentage similarity indices of the trawl sample matrix versus depth/sounding. 
in the results of the demersal tows was Micromesistius poutassou $(190-200-43 \%$; $280-318-64 \% ; 397-414 \mathrm{~m}-50 \%$ ). This is understandable as $M$. poutassou is a predominantly pelagic slope-dweller $(300-500 \mathrm{~m}$ depth), but with a known tendency to impinge on the bottom where this traverses its depth distribution (Bailey 1982). No demersal species, on the other hand, were so ranked among the pelagic mid-Trough samples. Only in the pelagic tows over the slope were demersal species (three) present in sufficient proportion to warrant inclusion. Remembering the close proximity to the bottom of the pelagic trawl $(0-10 \mathrm{~m}-1$ tow; $3-18 \mathrm{~m}-7$ tows; $60 \mathrm{~m}-1$ tow) such a total is noteworthy. This is especially so when the nature of the species is considered. The most important contribution was by Halargyreus johnsonii (598-637m-12\%), Synaphobranchus kaupi $(8 \%)$ and Coryphaenoides rupestris (3\%, both in 794-841 m). Most $S$. kaupi were immediately post-metamorphic juveniles and the $H$. johnsonii were again juvenile, stages when both are more likely to occur well off the sea bed.

Despite the obvious limitations of this preliminary investigation with large nets, this is the first substantial observation that the bulk of the populations of demersal and pelagic species remain separate over the slope, with the swimming layers of the former evidently very close to the bottom. Additional, more detailed investigation would clearly be rewarding.

Bailey, R. S. 1982. The population of the blue whiting in the North Atlantic. Advances in Marine Biology 19, 257-355.

\title{
Growth rates of deep-sea benthic animals in the Rockall Trough
}

\author{
J. D. Gage \\ Dunstaffnage Marine Research Laboratory, P.O. Box 3, Oban, Argyll PA34 4AD, \\ Scotland
}

There has been a prevailing view that life processes are very slow in the deep sea. This is based on rather sparse data from in situ studies of the sediment, microbial and fish respiration, and sediment recolonisation. Other in situ recolonisation observations indicate that certain species may settle and grow within a year or two. Estimates of age and growth rate of individual species are few, frequently based on few data and present no clear pattern. A well-known study, by means of radiometric dating, providing an estimate of what is thought to be an exceptionally slow rate of growth in a small-sized species of protobranch bivalve is subject to wide confidence limits.

The discovery of seasonal breeding in deep-sea species of echinoderms and bivalves offers the possibility of tracking the growth of age-marked cohorts in a time series of samples. This approach has been applied to a long time series of deep-sea hauls obtained using an epibenthic sledge at the Scottish Marine Biological Association's Permanent Station in the southern Rockall Trough. In order to make estimates of cohort age structure, methods of analysing the modal structure of size-frequency distributions have been applied. However, both because of individual variation in growth rate and because of growth curves resulting in 